BMJ Open Sport \& Exercise Medicine

\title{
Sports injuries and ill-health episodes in the Cali 2013 World Games
}

\author{
Paulo José Llinás, ${ }^{1}$ Rafael Fernando Serrano, ${ }^{1}$ Laureano Quintero Barrera, ${ }^{2}$ \\ Juan Carlos Quiceno Noguera, ${ }^{3}$ Juan Pablo Martinez Cano ${ }^{1,4}$
}

To cite: Llinás PJ, Serrano RF, Quintero Barrera L, et al. Sports injuries and ill-health episodes in the Cali 2013 World Games. BMJ Open Sport Exerc Med 2016;2: e000072. doi:10.1136/ bmjsem-2015-000072

- Prepublication history for this paper is available online. To view these files please visit the journal online (http://dx.doi.org/10.1136/ bmjsem-2015-000072).

Accepted 24 February 2016

CrossMark

${ }^{1}$ Department of Orthopaedics, Fundación Valle del Lili, Cali, Colombia

${ }^{2}$ Surgical Clinics Department, Universidad Javeriana, Cali, Colombia

${ }^{3}$ Sports Science Center,

Coldeportes, Bogotá,

Colombia

${ }^{4}$ Center for Clinical

Investigations, Fundación

Valle del Lili, Cali, Colombia

Correspondence to Dr Juan Pablo Martinez Cano; jpmartinezc@gmail.com

\section{ABSTRACT}

Background: The World Games is a multisport event, second in importance only to the Olympic Games. Systematic surveillance of injuries and ill-health episodes is an essential part of modern integral healthcare given to athletes.

Aim: To describe and analyse injuries and ill-health episodes affecting competitors during the Cali World Games 2013.

Methods: This is a cross-sectional study of injuries and ill-health episodes suffered by competing athletes. Entries to the registry were systematically recorded by official doctors and medical staff at the Games, and included attention to emergencies at the sport venues and data of reports received from health facilities around the city.

Results: In all, 2824 athletes, 1216 women and 1608 men, participated in the 2013 Cali World Games. There were 88 injuries and 29 ill-health episodes, for an overall incidence of 31.2 injuries and 10.3 ill-health episodes per 1000 athletes, over an 11 day period. The highest incidence of sport associated injuries affected jiu-jitsu athletes. Hands were the most common site of injury. Injury rates for men and women were 35.5 and $25.5 / 1000$ athletes, respectively, (RR $=1.41,95 \% \mathrm{Cl}$ 0.90 to $2.19, p=0.066$ ). National delegations with less than 25 athletes suffered more injuries compared to larger delegations, with 40.9 vs 29.2 injuries per 1000 athletes ( $\mathrm{RR} 1.4,95 \% \mathrm{Cl} 0.85$ to $2.30, \mathrm{p}=0.12$ ). The gastrointestinal system was the most affected by illness. The sport where most competitors suffered illhealth episodes was softball. The rate of ill-health episodes in women was $15 / 1000$, and for men 6.8/ 1000 athletes (RR=2.16, $95 \% \mathrm{Cl} 1.03$ to 4.56 , $\mathrm{p}=0.038$ ).

Conclusions: $3.1 \%$ of the athletes had sport-related injuries, and $1 \%$ had at least one episode of ill health. These are low numbers compared to other multisport events such as the Olympic Games. Men had a higher incidence of injuries, and women a higher incidence of episodes of ill health. Future World Games should improve data-collection strategies and develop preventive measures accordingly.

\section{INTRODUCTION}

In 1998, the Football International Federation (FIFA) began a registry of injuries occurring during France's World Soccer

\section{What are the new findings?}

The incidence of injuries and illnesses was low in the Cali 2013 World Games.

- Women have a higher risk of illness health episodes in this multisport event compared to men.

- Men might have a higher risk of injuries than women, but this was a non-significant difference.

Cup. $^{1-3}$ Following this initiative, the International Olympic Games Committee (IOC) implemented an injury surveillance system for multisport events since the 2008 Beijing Olympic Games. ${ }^{4}$ This initiative was then extended to surveillance of injuries and illnesses since the 2010 Vancouver Olympic Games. ${ }^{6}$ These examples of continuous surveillance of injuries and ill-health episodes are very important for athlete health protection. They are useful in the identification of risk factors associated and in the understanding of the mechanisms of injuries and illnesses.

Nowadays it is common that registries are published for different sport competitions, especially for popular sports like soccer, volleyball and swimming, among others. ${ }^{7-14}$ This kind of registry for sport competitions enables a better understanding of injuries and illnesses associated with the different disciplines involved. This knowledge helps to promote strategies to reduce the incidence of these pathologies and to treat them better in the future.

The World Games are organised every 4 years by the International World Games Association (IWGA) and could be considered the second multisport event in importance after the Olympic Games (summer and winter). The World Games include those sports and disciplines not officially included in the Olympic Games, but may also have one or more Olympic sports invited. The Cali 2013 World Games ('Cali Games') were held over a period of 11 days between 25 July 
and 4 August with 36 disciplines and 2824 athletes from 89 countries.

There are no surveillance studies for previous World Games competitions. Some sports that were included part in the World Games, such as jiu jitsu and wushu, have published surveillance studies involving those disciplines in national or continental martial arts events. ${ }^{15} 16$ Nevertheless, most of the sports that are part of the World Games have no previous suveillance studies. The aim of this study is to describe and analyse, for the first time for any World Games, the injuries and illnesses that occurred in the Cali 2013 Games.

\section{METHODS}

The IWGA injury and illness surveillance registry for multisport events was completed by the medical staff of the event: 30 general practitioners, 6 sports medicine physicians, 4 emergency medicine physicians, 3 trauma surgeons and 1 orthopaedic surgeon. Daily reports were also received from the five health centres in the city (Fundación Valle del Lili, Clínica Amiga, Centro Médico Imbanaco, DIME Clínica Neurocardiovascular and Clínica Oftalmológica). This information was recorded daily.

\section{Definition of injury and illness}

For the present study, injury was defined as any musculoskeletal (traumatic or overuse) disorder occurring at competition or training during the Cali World Games 2013 (25 July-4 August 2013) that required medical attention. All injuries were recorded, but in case of multiple injuries by a single incident to the same athlete, only the most severe one was recorded. Illness was defined as a medical condition, different to injury, which required medical attention. ${ }^{4} 617$

\section{Injury and illness report form}

The IWGA registry for medical attention includes: age, sex, sport, country, nature of the incident (injury/ illness), description of the incident, time and date of the incident, affected body system or anatomical area, diagnosis, treatment and estimated time loss for competition or training. This form is in English and it was distributed among the medical staff of the Cali Games. The medical staff participating in the study could understand and speak English.

\section{Confidentiality and ethical approval}

The name of the athlete and the nationality were used to avoid duplicates resulting from athletes treated for the same condition by the medical staff of the Cali Games and by a medical facility of the city. For any given duplicate, data were conciliated. Information was treated under complete confidentiality, kept secure, and made anonymous after checking for duplicates, by assigning a number to each participant.
The ethics committee of Fundación Valle del Lili Medical Centre in Cali, Colombia, approved this study.

\section{Data analysis}

The incidence (i) for injury and illness was calculated using the formula: $\mathrm{i}=\mathrm{n} / \mathrm{e}$, where $\mathrm{n}$ is the number of injuries or ill-health episodes during the study period and e the number of exposed athletes. The 95\% CI for the relative risk (RR) was calculated for injuries and illhealth episodes according to sports, sexes and delegations. The $\chi^{2}$ test was used to compare proportions. Injury and ill-health episode incidences are presented as means and rate ratios with $95 \%$ CI. $p$ Values $\leq 0.05$ were considered statistically significant. Stata V.13.0 was used.

\section{RESULTS}

A total of 2824 athletes participated in the Cali World Games 2013. Of these, 1216 were women $(43.1 \%)$ and 1608 men $(56.9 \%)$. During the Games, the medical staff looked after 160 episodes, 117 affecting athletes and 43 affecting judges, delegates and spectators. The distribution of injuries and diseases by genre and sport are shown in table 1 .

\section{Epidemiology of injuries}

There were a total of 88 injuries, in 88 athletes, for a global rate of 31.2 injuries per 1000 athletes and an overall incidence of injury of $3.1 \%$. In their order, the highest incidence in injuries was seen in: jiu-jitsu $(11.0 \%)$, roller inline hockey $(10.4 \%)$, karate $(10.2 \%)$, softball $(9.5 \%)$, rugby sevens $(8.3 \%)$ and artistic roller skating $(8.1 \%)$. The sports with the lowest incidence in injuries were field air sports, archery, billiard sports, canoe marathon, dancesport, gymnastics, racquetball, sumo, tug of war, waterskiing /wakeboarding and wushu, with no reported injuries. Injury rates for men and women were 35.5 and 25.5/1000 athletes, respectively, with an $\mathrm{RR}=1.41$ (95\% CI 0.90 to $2.19, \mathrm{p}=0.066$. There were no statistically significant differences between sexes in the global rate of injuries, or by sport.

The countries with the highest number of injured athletes were Colombia $(n=18)$, Italy $(n=11)$ and Venezuela $(n=5)$. Nevertheless, when the total number of athletes per delegation was taken into account, the leading country in injuries per total number of athletes was Greece (50\%), followed by Azerbaijan (20\%), Costa Rica $(20 \%)$ and Guatemala (14\%). There was a higher number of injured athletes in delegations with less than 25 athletes $(40.9 / 1000$ athletes) when compared to those with 25 or more athletes (29.2/1000 athletes), $\mathrm{RR}=1.42$ (95\% CI 0.83 to 2.35) (table 2).

Only 13 among the injured athletes $(15 \%)$ were estimated to have no time loss from competition, while the remaining 75 athletes $(85 \%)$ had injuries that prevented them from training or competing. It was estimated that there were $63(71 \%)$ athletes with injuries that resulted in an absence between 1-7 days, and 12 athletes (14\%) 
Table 1 Injuries, ill-health episodes and time loss per sport and genre in the Cali World Games 2013

\begin{tabular}{|c|c|c|c|c|c|c|c|c|c|c|c|c|}
\hline \multirow[b]{2}{*}{ Sports } & \multicolumn{3}{|c|}{ Female athletes } & \multicolumn{3}{|c|}{ Male athletes } & \multicolumn{3}{|c|}{ Female athletes } & \multicolumn{3}{|c|}{ Male athletes } \\
\hline & $\mathbf{n}$ & $\begin{array}{l}\text { Injuries } \\
\text { n (\%) }\end{array}$ & $\begin{array}{l}\text { Time } \\
\text { loss } \\
>7 \text { days } \\
\mathrm{n}(\%)\end{array}$ & $\mathbf{n}$ & $\begin{array}{l}\text { Injuries } \\
\text { n (\%) }\end{array}$ & $\begin{array}{l}\text { Time } \\
\text { loss } \\
>7 \text { days } \\
\mathrm{n}(\%)\end{array}$ & $\mathbf{n}$ & $\begin{array}{l}\text { Ill-health } \\
\text { episodes } \\
\text { n (\%) }\end{array}$ & $\begin{array}{l}\text { Time } \\
\text { loss } \\
>7 \text { days } \\
\mathrm{n}(\%)\end{array}$ & $\mathbf{n}$ & $\begin{array}{l}\text { III-health } \\
\text { episodes } \\
\text { n (\%) }\end{array}$ & $\begin{array}{l}\text { Time } \\
\text { loss } \\
>7 \text { days } \\
\text { n (\%) }\end{array}$ \\
\hline Acrobatic gymnastics & 36 & 0 & 0 & 38 & 0 & 0 & 36 & $1(2.8)$ & 0 & 38 & 0 & 0 \\
\hline Aerobic gymnastics & 58 & $1(1.7)$ & 0 & 51 & $1(2.0)$ & 0 & 58 & 0 & 0 & 51 & 0 & 0 \\
\hline Air sports & 10 & 0 & 0 & 55 & 0 & 0 & 10 & 0 & 0 & 55 & 0 & 0 \\
\hline Artistic roller skating & 19 & $1(5.3)$ & 0 & 18 & $2(11.1)$ & 0 & 19 & 0 & 0 & 18 & 0 & 0 \\
\hline Beach handball & 70 & $4(5.7)$ & 0 & 72 & $3(4.2)$ & $1(1.4)$ & 70 & 0 & 0 & 72 & 0 & 0 \\
\hline Billiard sports & 16 & 0 & 0 & 48 & 0 & 0 & 16 & 0 & 0 & 48 & 0 & 0 \\
\hline Boule sports & 32 & $1(3.1)$ & 0 & 34 & 0 & 0 & 32 & 0 & 0 & 34 & $1(2.9)$ & 0 \\
\hline Bowling & 24 & $1(4.2)$ & 0 & 24 & $2(8.3)$ & 0 & 24 & 0 & 0 & 24 & 0 & 0 \\
\hline Canoe marathon & 17 & 0 & 0 & 47 & 0 & 0 & 17 & 0 & 0 & 47 & 0 & 0 \\
\hline Canoe polo & 45 & 0 & 0 & 48 & $5(10.4)$ & $1(2.1)$ & 45 & 0 & 0 & 48 & $1(2.1)$ & 0 \\
\hline Dancesport & 65 & 0 & 0 & 65 & 0 & 0 & 65 & $1(1.5)$ & 0 & 65 & 0 & 0 \\
\hline Duathlon & 27 & 0 & 0 & 52 & $1(1.9)$ & 0 & 27 & 0 & 0 & 52 & $2(3.8)$ & 0 \\
\hline Field archery & 46 & 0 & 0 & 48 & 0 & 0 & 46 & $1(2.2)$ & 0 & 48 & $1(2.1)$ & 0 \\
\hline Finswimming & 42 & $1(2.4)$ & 0 & 42 & $1(2.4)$ & 0 & 42 & 0 & 0 & 42 & 0 & 0 \\
\hline Fistball & 0 & 0 & 0 & 54 & 1 (1.9) & $1(1.9)$ & 0 & 0 & 0 & 54 & $1(1.9)$ & 0 \\
\hline Flying disc & 34 & $1(2.9)$ & 0 & 44 & 0 & 0 & 34 & $2(5.9)$ & 0 & 44 & $1(2.3)$ & 0 \\
\hline Jiu-jitsu & 38 & $4(10.5)$ & 0 & 53 & $6(11.3)$ & $2(3.8)$ & 38 & $1(2.6)$ & 0 & 53 & 0 & 0 \\
\hline Karate & 46 & $2(4.3)$ & 0 & 42 & 7 (16.7) & $2(4.8)$ & 46 & 0 & 0 & 42 & 0 & 0 \\
\hline Korfball & 56 & $1(1.8)$ & $1(1.8)$ & 63 & $3(4.8)$ & $1(1.6)$ & 56 & 0 & 0 & 63 & $1(1.6)$ & 0 \\
\hline Life saving & 50 & 0 & 0 & 50 & $1(2.0)$ & 0 & 50 & 0 & 0 & 50 & 0 & 0 \\
\hline Orienteering & 40 & 0 & 0 & 39 & $2(5.1)$ & 0 & 40 & 0 & 0 & 39 & 0 & 0 \\
\hline Powerlifting & 40 & 0 & 0 & 40 & $1(2.5)$ & $1(2.5)$ & 40 & 0 & 0 & 40 & 0 & 0 \\
\hline Racquetball & 16 & 0 & 0 & 16 & 0 & 0 & 16 & 0 & 0 & 16 & 0 & 0 \\
\hline Rhythmic gymnastics & 23 & 0 & 0 & 0 & 0 & 0 & 23 & 0 & 0 & 0 & 0 & 0 \\
\hline Roller inline hockey & 0 & 0 & 0 & 106 & $11(10.4)$ & $2(1.9)$ & 0 & 0 & 0 & 106 & $2(1.9)$ & 0 \\
\hline Rugby & 0 & 0 & 0 & 96 & $8(8.3)$ & 0 & 0 & 0 & 0 & 96 & $1(1.0)$ & 0 \\
\hline Softball & 95 & $9(9.5)$ & $1(1.1)$ & 0 & 0 & 0 & 95 & $6(6.3)$ & 0 & 0 & 0 & 0 \\
\hline $\begin{array}{l}\text { Speed skating road and } \\
\text { track }\end{array}$ & 38 & 5 (13.2) & $2(5.3)$ & 41 & 0 & 0 & 38 & 5 (13.2) & $1(2.6)$ & 41 & 0 & 0 \\
\hline Sport climbing & 34 & 0 & 0 & 34 & $1(2.9)$ & 0 & 34 & 0 & 0 & 34 & 0 & 0 \\
\hline Squash & 18 & 0 & 0 & 21 & $1(4.8)$ & 0 & 18 & 0 & 0 & 21 & 0 & 0 \\
\hline Sumo & 48 & 0 & 0 & 48 & 0 & 0 & 48 & 0 & 0 & 48 & 0 & 0 \\
\hline Trampoline gymnastics & 31 & 0 & 0 & 41 & 0 & 0 & 31 & 0 & 0 & 41 & 0 & 0 \\
\hline Tug of war & 54 & 0 & 0 & 88 & 0 & 0 & 54 & 0 & 0 & 88 & $1(1.1)$ & $1(1.1)$ \\
\hline Waterski-wakeboard & 28 & 0 & 0 & 53 & 0 & 0 & 28 & 0 & 0 & 53 & 0 & 0 \\
\hline Wushu & 20 & 0 & 0 & 37 & 0 & 0 & 20 & 0 & 0 & 37 & 0 & 0 \\
\hline Total & 1216 & $31(2.5)$ & $4(0.3)$ & 1608 & $57(3.5)$ & $11(0.7)$ & 1216 & $17(1.4)$ & $1(0.1)$ & 1608 & $12(0.7)$ & $1(0.1)$ \\
\hline
\end{tabular}


Table 2 Injuries and ill-health episodes according to the size of the national delegation

\begin{tabular}{|c|c|c|c|c|c|}
\hline & \multicolumn{4}{|c|}{ Size of delegation (number of athletes) } & \multirow[b]{2}{*}{ Total } \\
\hline & $<25$ & $25-49$ & $50-99$ & $>100$ & \\
\hline Delegations $n$ & 57 & 11 & 16 & 5 & 89 \\
\hline Athletes n (\%) & $464(16)$ & $399(14)$ & $1216(43)$ & $745(26)$ & 2824 \\
\hline Injuries n (\%) & $19(21)$ & $10(11)$ & $35(40)$ & $24(27)$ & 88 \\
\hline Incidence of injuries $\times 1000$ Athletes & 40.9 & 25.1 & 28.8 & 32.2 & 31.2 \\
\hline III-health episodes n (\%) & $4(13)$ & $5(17)$ & $10(34)$ & $10(34)$ & 29 \\
\hline Incidence of ill-health episodes $\times 1000$ Athletes & 8.6 & 12.5 & 8.2 & 13.4 & 10.3 \\
\hline
\end{tabular}

with more than 7 days of absence from sports practice. The sports with the highest time of absence from training or competing were karate and jiu-jitsu.

The most common site of injury was the hand with nine injuries (over $50 \%$ occurred in athletes competing in softball), followed by the head and the knee, with five injuries each. Other parts of the upper and lower extremities were injured in 24 more athletes. National delegations with fewer than 25 athletes had the highest incidence of injuries, 40.9 injuries per 1000 athletes. When compared to national delegations with more than 25 athletes (29.2 injuries per 1000 athletes) the OR was $1.42(\mathrm{p}=0.18)$.

The most common types of injuries were contusions $(30.7 \%)$, followed by overuse injuries $(19.3 \%)$, wounds $(15.9 \%)$ and fractures $(11.3 \%)$. Most contusions occurred in jiu-jitsu (23.1\%), rugby $(19.2 \%)$ and karate $(15.4 \%)$. Roller inline hockey and speed skating road together accounted for $40 \%$ of all fractures. Martial arts (karate and jiu-jitsu) led in wounds incidence $(42.8 \%$ ) and canoe polo in overuse injuries $(25 \%)$.

\section{Epidemiology of ill-health episodes}

There were a total of 29 ill-health episodes, in 27 athletes, among the 2824 athletes, resulting in an incidence of $1 \%$ or 10.3 illnesses per 1000 athletes. The rate of illnesses in women was $15 / 1000$ athletes, and in men it was $6.8 / 1000$ athletes. The incidence of illnesses was significantly higher in women compared to men, $\mathrm{RR}=2.16$ (95\% CI 1.03 to $4.56, \mathrm{p}=0.038$ ). There were no significant differences between sexes for individual sports.

The system most commonly affected was the gastrointestinal system $(n=8)$ followed by the respiratory system $(n=7)$. The main illness for male athletes was respiratory infections $(n=3)$ among the total viral infections $(n=5)$. For female athletes, the main illnesses were headache $(n=3)$, gastrointestinal $(n=3)$ and respiratory infections $(n=2)$. Ninety-three $(93 \%)$ of the illnesses caused a time loss from sport of less than 7 days. Only $7 \%$ had a time loss from sport greater than 7 days, and no one had a time loss above 30 days.

Softball was the sport associated with more episodes of ill health (with $21 \%$ of the total number of athletes falling ill), followed by speed skating (17\%), flying disc $(10 \%)$, field archery (7\%) and duathlon (7\%). The countries with the most number of ill athletes were Colombia $(n=5)$, Argentina $(n=3)$ and Latvia $(n=2)$. When the total number of athletes per delegation was taken into account, the leading country in illnesses per total number of athletes was Thailand (9\%), followed by Aruba (7\%), Latvia $(6 \%)$ and Slovakia $(6 \%)$.

\section{DISCUSSION}

The 11-day Cali Games had an incidence of $3.1 \%$ and $1 \%$ athletes suffering from at least one injury or illness, respectively. This is an overall rate of 31.2 injuries and 10.3 illnesses per 1000 athletes. The highest rates of injuries were recorded in jiu-jitsu, karate and roller inline hockey, while speed skating, softball and flying disc had the highest rates of ill athletes.

There are no reports of injuries or illnesses in previous World Games, a fact precluding comparisons with our results or evaluation of trends. This registry allows future comparisons with the next World Games. However, a comparison with previous Olympic Games is possible. In the London Olympic Games 2012, the overall rates were 128.8 injuries per 1000 athletes and 71.7 illnesses per 1000 athletes, from a total of 10568 athletes. ${ }^{4}$ This represents a risk 4.12 times higher of having an injury and 6.96 times higher of having an illness, compared to the Cali Games. With 2824 athletes, the Cali Games had 3.74 times less athletes than the London Olympic Games. Our results can be due to the under-reporting of injuries and episodes of ill health, which were measured for the first time for the World Games. For multiple injuries in the same athlete, only the most severe injury was recorded, which certainly can generate an underestimation of the real incidence. Data from athletes with team physicians as part of their national delegation could have been missed because they never were treated by the Cali Games physicians, were not attended to at the local hospitals, and were probably not reported, since the reporting of injuries or illnesses was not mandatory. This can be improved for future World Games competitions by making the reporting of injuries or episodes of ill-health episodes mandatory.

In the Cali Games, we found that while $86 \%$ of the injuries produced an estimated time loss between 0 and 7 days, only 11 athletes $(12.5 \%)$ had a time loss greater 
than 30 days, usually related to severe trauma such as fractures. Most of the injuries in the London Olympic Games $(65 \%)$ had no absence from competition or training, 35\% had an estimated time loss of at least 1 day from training or competition, while $13 \%$ had an estimated time-loss greater than 7 days. This estimated time loss related to injuries is similar between the Cali Games and the London Olympic Games.

In the Cali Games, hands were the most common site of injury, followed by the head and knees, whereas in the Beijing Olympic Games 2008 the most commonly affected sites were the thighs and the knees. ${ }^{5}$

The most common types of injuries were contusions $(30.7 \%)$, followed by overuse injuries $(19.3 \%)$, wounds $(15.9 \%)$ and fractures $(11.3 \%)$. In the London Olympic Games, the mechanisms most frequently reported were overuse injury (25\%), non-contact trauma (20\%), contusion with another athlete $(14 \%)$ and contusion with a stationary object $(12 \%){ }^{4}$

According to different registries of sports illnesses and injuries, there are differences in the incidence of pathologies for each sport. This shows the natural fluctuation and variability of athletes' exposure to risk, which further emphasises the usefulness of this type of descriptive and ongoing surveillance studies to monitor trends over time. Maintaining and improving World Games registries is fundamental to achieving this.

Both in the Cali World Games and the London Olympic games, there were more illnesses affecting women than men. In the Cali Games, women had 15.0 episodes of ill health per 1000 athletes compared to $6.8 / 1000$ athletes for men. In the London Olympic games, the incidence was $86.0 / 1000$ for women and 53.3 illnesses per 1000 athletes for men. Men had a higher incidence of injuries in the Cali Games, 35.0 injuries per 1000 athletes, compared to women with 25 injuries per 1000 athletes. This is similar to what occurred in the Beijing Olympic Games (54.2\% injuries in men) but different to that in London, where women had a higher incidence of injuries than men, 132.8 vs 121.0 injuries per 1000 athletes. Once again, the higher numbers observed in the London and Beijing Olympic games may be due to under-registration in the Cali Games.

Incidence usually considers the time exposed to risk as the denominator; however, in our study, the incidence of injuries or illnesses was expressed as the number of new cases per 1000 athletes. This is the recommendation of the International Olympic Committee for multisport events like the World Games. These types of surveillance studies are essential to identify and subsequently reduce the incidence of injuries and illnesses in sport competitions, which can also reduce the direct and indirect costs associated. Continuous monitoring in time can determine the true effect of the preventive measures implemented on the incidence of injuries and illnesses. This is the first study of its kind for a World Games competition and it represents a baseline for future events. There are some challenges such as the limited data- collection window, the monitoring of a large number of records in scarce time, the large amount of people involved in the event data-recording process, and the possibility of under-registration, which can all affect the quality of the information.

Under-reporting might be the principal limitation of this study. From the total 117 injury/illness episodes, 35 were from the medical institutions in the city $(30 \%)$. The remaining 82 injury/illness episodes $(70 \%)$ were evaluated by the medical staff at the World Games locations. The response rate for these data is thought to be $100 \%$. Nevertheless, it was not measured. There are two main possible sources for under-reporting: first, athletes with minor injuries or illnesses that did not looked for medical attention; but this is a problem that may be present in every surveillance study conducted for a multisport event. The other reason are athletes that did not searched fot medical attention from the organisation but were only treated by the doctor in their national delegation. This was not previously contemplated by the study design and may be the principal cause for underreporting. Though, this group must include mainly minor injuries or illnesses that did not required any X-rays, laboratories, additional specialised treatment nor caused absence from training or competition. For future World Games events, response rates should be measured and national delegations asked to provide their data about injuries and ill-health episodes.

The International World Games Association should develop an electronic health recording system that could improve data collection with all the variables of interest and that may help to monitor those athletes who are injured or have fallen ill. This record should be mandatory for every national delegation, regardless of whether the athlete is treated by the official physicians of the event or by the physicians of the delegation. This can improve both the quality and completeness of the data collected.

\section{CONCLUSION}

During the Cali World Games, 3.1\% of athletes had an injury, and $1 \%$ had an illness episode. These are low numbers compared to previous multisport events such as the recent Olympic Games. Men had a higher incidence of injuries and women a higher incidence of illnesses. Future World Games should improve the data-collection strategies and include the development of preventive measures suited to each specific sport.

Acknowledgements The authors would like to thank Dr Jairo Osorno for his help in the final version of the manuscript.

\section{Collaborators Jairo Osorno.}

Contributors RFS and PJL had the idea for the study. It was planned by RFS, PJL and JPMC. The methodology was designed by RFS and JPMC. The study was conducted and reported by RFS, JPMC, JCQN and LQ. The study was analysed and the paper was written by JPMC, RFS and PJL. With final approval of the five authors. Jairo Osorno contributed in the final edition of the manuscript

Competing interests None declared. 
Ethics approval Fundación Valle del Lili Ethics committee.

Provenance and peer review Not commissioned; externally peer reviewed.

Open Access This is an Open Access article distributed in accordance with the Creative Commons Attribution Non Commercial (CC BY-NC 4.0) license, which permits others to distribute, remix, adapt, build upon this work noncommercially, and license their derivative works on different terms, provided the original work is properly cited and the use is non-commercial. See: http:// creativecommons.org/licenses/by-nc/4.0/

\section{REFERENCES}

1. Dvorak J, Junge A, Derman W, et al. Injuries and illnesses of football players during the 2010 FIFA World Cup. Br J Sports Med 2011;45:626-30.

2. Junge A. Football injuries during FIFA tournaments and the Olympic Games, 1998-2001: development and Implementation of an injury-reporting system. Am J Sports Med 2004;32:80S-9S

3. Junge A. Football injuries during the World Cup 2002. Am J Sports Med 2004;32:23S-27.

4. Engebretsen L, Soligard T, Steffen $\mathrm{K}$, et al. Sports injuries and illnesses during the London Summer Olympic Games 2012. Br J Sports Med 2013;47:407-14.

5. Junge A, Engebretsen L, Mountjoy ML, et al. Sports injuries during the Summer Olympic Games 2008. Am J Sports Med 2009;37:2165-72.

6. Engebretsen L, Steffen K, Alonso JM, et al. Sports injuries and illnesses during the Winter Olympic Games 2010. Br J Sports Med 2010:44:772-80.

7. Alonso JM, Edouard P, Fischetto G, et al. Determination of future prevention strategies in elite track and field: analysis of Daegu 2011
IAAF Championships injuries and illnesses surveillance. $\mathrm{Br} J$ Sports Med 2012;46:505-14.

8. Alonso JM, Tscholl PM, Engebretsen L, et al. A Occurrence of injuries and illnesses during the 2009 IAAF World Athletics Championships. Br J Sports Med 2010; 44:1100-5.

9. Bahr R, Reeser JC. Injuries among world-class professional beach volleyball players. Am J Sports Med 2003;31:119-25.

10. Fuller CW, Laborde F, Leather RJ, et al. International Rugby Board Rugby World Cup 2007 injury surveillance study. Br J Sports Med 2008:42:452-9.

11. Le Gall F, Carling C, Reilly T. Injuries in young elite female soccer players: an 8-season prospective study. Am J Sports Med 2008;36:276-84.

12. Junge A, Langevoort G, Pipe A, et al. Injuries in team sport tournaments during the 2004 Olympic Games. Am J Sports Med 2006;34:565-76.

13. Mountjoy M, Junge A, Alonso JM, et al. Sports injuries and illnesses in the 2009 FINA World Championships (Aquatics). Br J Sports Med 2010;44:522-7.

14. Theron N, Schwellnus M, Derman W, et al. Illness and injuries in Elite football players-a prospective cohort study during

the FIFA Confederations Cup 2009. Clin J Sport Med 2013;23:379-83.

15. Scoggin JF III, Brusovanik G, Izuka BH, et al. Assessment of injuries during Brazilian Jiu-Jitsu competition. Orthop J Sports Med 2014;2:2325967114522184.

16. Yiemsiri $P$, Wanawan A. Prevalence of injuries in Wushu competition during the 1st Asian Martial Arts Games 2009. J Med Assoc Thai 2014;97(Suppl 2):S9-13.

17. Armsey TD, Hosey RG. Medical aspects of sports: epidemiology of injuries, preparticipation physical examination, and drugs in sports. Clin Sports Med 2004;23:255-79. 